\title{
DEVELOPMENT OF MESALAZINE MICROSPHERES FOR COLON TARGETING
}

\author{
KATTA RAJESH, R. DEVESWARAN", S. BHARATH, B. V. BASAVARAJ \\ Department of Pharmaceutics, Faculty of Pharmacy, M. S. Ramaiah University of Applied Sciences, Bangalore 560054 \\ Email: deveswaran.ps.ph@msruas.ac.in
}

Received: 28 Jan 2017, Revised and Accepted: 14 Jun 2017

\begin{abstract}
Objective: The present work was aimed at preparation of mesalazine microspheres by a non-aqueous solvent evaporation method using eudragit $\mathrm{S}$ 100 and eudragit L 100 as $\mathrm{pH}$ dependent polymers for colon targeting.

Methods: The ratio of drug to polymer was varied and the effect of formulation variables revolutions per minute (RPM) (1000, 1500, 2000 and $2500)$ and concentration of span $80(1 \%, 1.5 \%, 2 \%$ and $2.5 \%)$ were studied. Prepared microspheres were evaluated for particle size, percent drug entrapment, granular analysis, in vitro drug release studies, Fourier transformed infrared spectroscopy (FT-IR) Differential Scanning Calorimetry
\end{abstract} (DSC), X-ray diffraction (XRD) and scanning electron microscopy (SEM) studies.

Results: Particle size has decreased and percent drug entrapment had increased with increase in RPM in all formulations. When the span 80 concentration increased, the particle size of the microsphere formulations increased and percent drug entrapment decreased in eudragit S 100 microspheres; whereas in eudragit L 100 microspheres, as the concentration of span 80 increased, the particle size of the microsphere formulations decreased. The prepared microspheres sustained the drug release over a period of $12 \mathrm{~h}$.

Conclusion: Thus eudragit S 100 and eudragit L 100 microspheres could constitute a promising approach for colon-specific and sustained delivery of mesalazine for the treatment of inflammatory bowel disease.

Keywords: Microspheres, Mesalazine, Eudragit S 100, Solvent evaporation, Inflammatory bowel disease

(C) 2017 The Authors. Published by Innovare Academic Sciences Pvt Ltd. This is an open access article under the CC BY license (http://creativecommons.org/licenses/by/4.0/) DOI: http://dx.doi.org/10.22159/ijap.2017v9i4.17326

\section{INTRODUCTION}

Oral drug delivery system is one of the frontier areas of delivering a drug with the cost-effectiveness of dosage form and treatment, patient compliance, optimum drug delivery and bioavailability [1]. There has been a remarkable improvement in the field of novel drug delivery systems. Carrier technology is an approach for drug delivery by the union of the drug to a carrier particle such as microspheres, nanoparticles, liposomes, etc. which modulates the release and absorption characteristics of the drug [2].

Colon-specific drug delivery systems have gained increasing attention for the treatment of diseases such as Crohn's disease, ulcerative colitis and irritable bowel syndrome [3]. Single unit dosage forms such as tablets and capsules for modified release colonic delivery suffer from problems such as unpredictable gastric emptying, gastrointestinal (GI) transit variations resulting from inter-subject variability in transit patterns and incomplete drug delivery in GI tract due to the risk of not dissolving the polymer coat on the large, low surface area coated tablets. On the other hand, multi-particulate drug delivery system for colonic delivery shows several advantages over single-unit dosage forms. Being of smaller size, it is expected to provide less inter and intra-individual variability, more rapid and uniform gastric emptying, more uniform dispersion and reproducible transit through GI tract [4, 5]. However, in microparticulate delivery systems, it is challenging to develop a colon-targeted sustained-release dosage form. Microspheres are homogeneous, monolithic particles which improve the treatment by providing localization of the drug at the site of action and by prolonging the drug release [6]. It suffers from the risk of early dissolution and release of the drug before reaching the colon due to its large surface area $[7,8]$.

Mesalazine (5-aminosalicylic acid, 5-ASA) is widely used in longterm treatment of ulcerative colitis by its topical mode of action on the inflammation in colonic mucosa. In order to achieve effective oral mesalazine treatment with minimal side effect and acceptable patient compliance, the delivery system has to overcome many obstacles. The effective use of the majority of the currently marketed mesalazine formulations requires multiple daily dosing with up to 12 tablets or capsules $[9,10]$.
Upon oral administration, mesalazine exhibits rapid and nearly complete absorption from the upper intestine, resulting not only in systemic side effects but also in lowering the dose reaching the colon with the subsequently decreased probability of therapeutic success [11]. In ulcerative colitis, inflammation is observed in all regions of the colon. Accordingly, in order to overcome these problems, in formulating mesalazine in a successful delivery system, it is important to minimise 5-ASA release in the upper gastrointestinal tract and to localize mesalazine release in the colon in a sustained release manner. If mesalazine is released in a pulsatile manner in the ascending colon, it would be diluted during its passage in the colon, consequently, a scarce concentration of mesalazine could be delivered to the transverse and descending colon resulting in reduced clinical effectiveness.

This is more difficult in the case of mesalazine due to its physiochemical properties. mesalazine exhibits amphoteric property, its solubility is increased at acidic $\mathrm{pH}$ values $(\mathrm{pH}<2)$ in the stomach and at more alkaline values $(\mathrm{pH}>5.5)$ in the lower part of the small intestine. This necessitates the development of $\mathrm{pH}$-dependent, colontargeted, sustained release mesalazine microspheres. The goal of this work was to prepare mesalazine microspheres by a non-aqueous solvent evaporation method employing $\mathrm{pH}$-dependent polymers like eudragitS100 and eudragit L 100.

\section{MATERIALS AND METHODS}

\section{Materials}

Mesalazine was purchased from BEC Chemicals, Mumbai. Eudragit S 100 and Eudragit L 100 were procured from Yarrow Chem Products, Mumbai. Magnesium stearate was purchased from Central Drug House Pvt. Limited, New Delhi. Acetone and liquid paraffin heavy was purchased from Rankem, New Delhi. Span 80 was purchased from NR CHEM, Mumbai. All other reagents used were of analytical grade.

\section{Experimental methods}

Preparation of microspheres

Microspheres containing mesalazine were prepared by a nonaqueous solvent evaporation technique. Mesalazine and the 
specified amount of magnesium stearate were dispersed in acetone to which eudragit S 100 was previously dissolved. The resulting suspension was added at once to a specified amount of liquid paraffin containing $2 \%(\mathrm{v} / \mathrm{v})$ span 80 and stirred at 1500 revolutions per minute (RPM) for $3 \mathrm{~h}$ using a mechanical stirrer under ambient conditions (table 1). Stirring was continued until the organic solvent evaporated completely. The microspheres were filtered, washed with n-hexane, dried overnight and then stored in desiccators until further use [12]. The same procedure was repeated using eudragit L 100 .

Table 1: Batch specifications of preliminary formulations

\begin{tabular}{lllll}
\hline S. No. & Formulation code & Drug: polymer ratio & Stirring speed (RPM) & Emulsifier Concentration (\%) \\
\hline 1 & F1 & $1: 1$ & 1500 & 2 \\
2 & F2 & $1: 2$ & 1500 & 2 \\
3 & F3 & $1: 3$ & 1500 & 2 \\
4 & F4 & $1: 4$ & 1500 & 2 \\
5 & F5 & $1: 5$ & 1500 & 2 \\
6 & F6 & $1: 1$ & 1500 & 2 \\
7 & F7 & $1: 2$ & 1500 & 2 \\
8 & F8 & $1: 3$ & 1500 & 2 \\
9 & F9 & $1: 4$ & 1500 & 2 \\
10 & F10 & $1: 5$ & 1500 & 2 \\
\hline
\end{tabular}

\section{FT-IR studies}

The drug and polymer interactions were studied by Fourier transform infrared spectroscopy by $\mathrm{KBr}$ disc method. The spectra were recorded for the pure drug, polymer and the physical mixture of drug and polymer in the ratio $1: 1$ at the scanning range of 400$4000 \mathrm{~cm}^{-1}$ using FTIR-8400S, spectrophotometer (SHIMADZU, Japan).

\section{DSC studies}

The DSC analysis of pure drug, polymer and the physical mixture of drug and polymer were carried out using differential scanning calorimeter (PERKIN ELMER-Pyris 1). Samples of about $5 \mathrm{mg}$ was placed in a $50 \mu \mathrm{l}$ perforated aluminium pan and sealed. Heat runs for each sample were set from $5{ }^{\circ} \mathrm{C}$ to $300{ }^{\circ} \mathrm{C}$ using nitrogen as purging gas and samples were analyzed.

\section{XRD studies}

Powder XRD of mesalazine, eudragit S-100, eudragit L-100, Formulation mixture of mesalazine with eudragit S-100, Formulation mixture of mesalazine with eudragit L-100 was recorded using Bruker AXS D8 Advance diffractometer with Si(Li) PSD detector. The operation data were: measuring circle diameter435,500 and $600 \mathrm{~mm}$ predetermined; angle range- $360^{\circ}$; X-ray source-Cu, wavelength $1.5406 \mathrm{~A}^{0}$.

\section{Characterization of prepared microspheres}

\section{Micromeritic studies}

The microspheres were characterized for their micromeritic properties such as tap density, bulk density, Carr's index, Hausner's ratio and angle of repose. All the analysis was carried out in triplicate [13].

\section{Yield of microspheres}

The percentage yield of microspheres was calculated by the following formula,

$$
\% \text { yield }=\frac{\text { Actual weight of product }}{\text { Total weight of drug and excipient }} \times 100
$$

\section{Scanning electron microscopy}

The surface morphology of prepared microspheres was observed under scanning electron microscope (JEOL, JSM-T, Japan). Dry microspheres were placed on an electron microscope brass stub and coated with gold to a thickness of about $200 \mathrm{~A}^{\circ}$ using a sputter coater in an ion sputter. Pictures of the microspheres were taken by randomly scanning the stub with the help of SEM analyzer.

\section{Particle size determination}

The microspheres were observed under $100 \mathrm{X}$ magnification in an optical microscope (Olympus LITE image) and an average of 100 particles was counted.

\section{Drug entrapment efficiency}

Accurately weighed the quantity of microspheres equivalent to 100 $\mathrm{mg}$ of mesalazine was taken in $100 \mathrm{ml}$ volumetric flask and dissolved in $50 \mathrm{ml}$ of $25 \%$ sodium acetate solution using sonication for $15 \mathrm{~min}$ and the volume was made up to $100 \mathrm{ml}$ with $25 \%$ sodium acetate solution. The resulting solution was diluted suitably with water and filtered through Whatman filter paper No: 41. The absorbance of the resulting solution was measured at $240 \mathrm{~nm}$, using distilled water as a blank. All the analysis was carried out in triplicate. The percentage drug entrapment was determined using the following equation,

$\%$ drug entrapment efficiency

$$
=\frac{\text { Amount of drug actually present }}{\text { Theoritical drug loaded expected }} \times 100
$$

\section{In vitro drug release studies}

In vitro drug release was studied using dissolution test apparatus USP type I method (rotating basket method). The drug loaded microspheres equivalent to $100 \mathrm{mg}$ of mesalazine were introduced into $900 \mathrm{ml}$ of dissolution medium which was maintained at $37 \pm 0.5^{\circ} \mathrm{C}$ and stirred at $100 \mathrm{rpm}$. The dissolution was carried out in $0.1 \mathrm{~N}$ hydrochloric acid for first $2 \mathrm{~h}$ followed by $4.5 \mathrm{pH}$ acetate buffer for next $2 \mathrm{~h}$ and $7.4 \mathrm{pH}$ buffers containing rat fecal content for next $8 \mathrm{~h}$ to mimic the GIT transit to colon region [14]. $5 \mathrm{ml}$ of the aliquot was withdrawn at regular predetermined intervals and sink conditions were maintained throughout the study by replacing an equal volume of fresh dissolution medium. The samples were diluted suitably with distilled water and analysed spectro-photometrically at $240 \mathrm{~nm}$. All the analysis was carried out in triplicate.

\section{Drug release kinetics}

Data obtained from in vitro drug release studies were fitted to various kinetic models like zero-order, $1^{\text {st }}$ order, Higuchi, Korsemeyer and Peppas using PCP Disso V2 software to predict the drug release mechanism.

\section{Stability studies}

Based on the International Conference on Harmonization (ICH) guidelines $[15,16]$ the stability studies were carried out in an environmental chamber (Tempo Instruments, India). Microsphere formulations F13 and F20 were stored at $40{ }^{\circ} \mathrm{C} \pm 2{ }^{\circ} \mathrm{C}$ and $75 \% \pm 5 \%$ $\mathrm{RH}$ for a period of $6 \mathrm{mo}$. At intervals of $0,2,4$ and 6 mo for accelerated storage condition, the samples were tested for changes in physical appearance and drug content.

\section{RESULTS AND DISCUSSION}

\section{FTIR studies}

Eudragit S 100 (in fig. 1a)showed hydroxyl group stretching (-OH) at $2989 \mathrm{~cm}^{-1}$, alkyl group (CH-R) stretching at $2997 \mathrm{~cm}^{-1}$, the ester 
linkage $(\mathrm{C}=0-\mathrm{O}-\mathrm{R})$ stretching at $1726 \mathrm{~cm}^{-1}$, carboxylic acid $(\mathrm{C}=\mathrm{O}-\mathrm{OH})$ stretching was observed at $1708 \mathrm{~cm}^{-1}$, alkyl group (CH-R) bending at $1386,1448,1483 \mathrm{~cm}^{-1}$ and carboxylic acid bending peaks at 1159 , $1188,1263 \mathrm{~cm}^{-1}$. Fig. 1b represents the FT-IR spectra of eudragit L 100. The characteristic peaks of eudragit $\mathrm{L} 100$ are hydroxyl group stretching $(-\mathrm{OH})$ at $3494 \mathrm{~cm}^{-1}$, alkyl group (CH-R) stretching at 2993 $\mathrm{cm}^{-1}$, the ester linkage (C=0-0-R) stretching at $1784 \mathrm{~cm}^{-1}$, carboxylic acid $(\mathrm{C}=0-\mathrm{OH})$ stretching at $1724 \mathrm{~cm}^{-1}$, alkyl group (CH-R) bending at $1384,1448,1487 \mathrm{~cm}^{-1}$ and carboxylic acid bending peaks at 1161 , $1186,1261 \mathrm{~cm}^{-1}$. Magnesium stearate showed absorptions peaks at 2914 and $2486 \mathrm{~cm}^{-1}$ due to $\mathrm{C}-\mathrm{H}$ stretching of the molecule. The other bands located at 1581, $1476 \mathrm{~cm}^{-1}$ are due to the C00-group stretching (in fig. 1c).
The characteristic peaks of mesalazine are carboxylic acid stretch R$\mathrm{C}=\mathrm{O}-\mathrm{OH}$ with peaks at 3342 and $1315 \mathrm{~cm}^{-1}, \mathrm{C}=0$ stretch at $1789 \mathrm{~cm}^{-}$ $1,-\mathrm{C}_{6} \mathrm{H}_{5}$ aromatic ring stretch at $1645 \mathrm{~cm}^{-1},-\mathrm{C}-\mathrm{H}$ (aromatic) stretch at $1450 \mathrm{~cm}^{-1}$ and- $\mathrm{C}=\mathrm{C}$ (aromatic) at $1490 \mathrm{~cm}^{-1}$. The bending peaks of meta, para-substituted benzene was observed at $811 \mathrm{~cm}^{-1}$ and the R$\mathrm{NH}_{2}$ bending peak was observed at $686 \mathrm{~cm}^{-1}$ (fig. 1d). FT-IR spectra of physical mixture of mesalazine with eudragit S 100 and eudragit $\mathrm{L}$ 100 showed characteristic peaks of carboxylic acid stretch $\mathrm{R}-\mathrm{C}=\mathrm{O}$ $\mathrm{OH}$, observed at 3409 and $1315 \mathrm{~cm}^{-1}, \mathrm{C}=0$ stretch at $1789 \mathrm{~cm}^{-1},-\mathrm{C}_{6} \mathrm{H}_{5}$ aromatic ring stretch at $1645 \mathrm{~cm}^{-1},-\mathrm{C}-\mathrm{H}$ (aromatic) stretch at 1452 $\mathrm{cm}^{-1}$ and $-\mathrm{C}=\mathrm{C}$ (aromatic) stretch at $1490 \mathrm{~cm}^{-1}$. The above results confirmed the absence of drug interaction within the polymers (fig. 1e and $1 \mathrm{f}$ ).

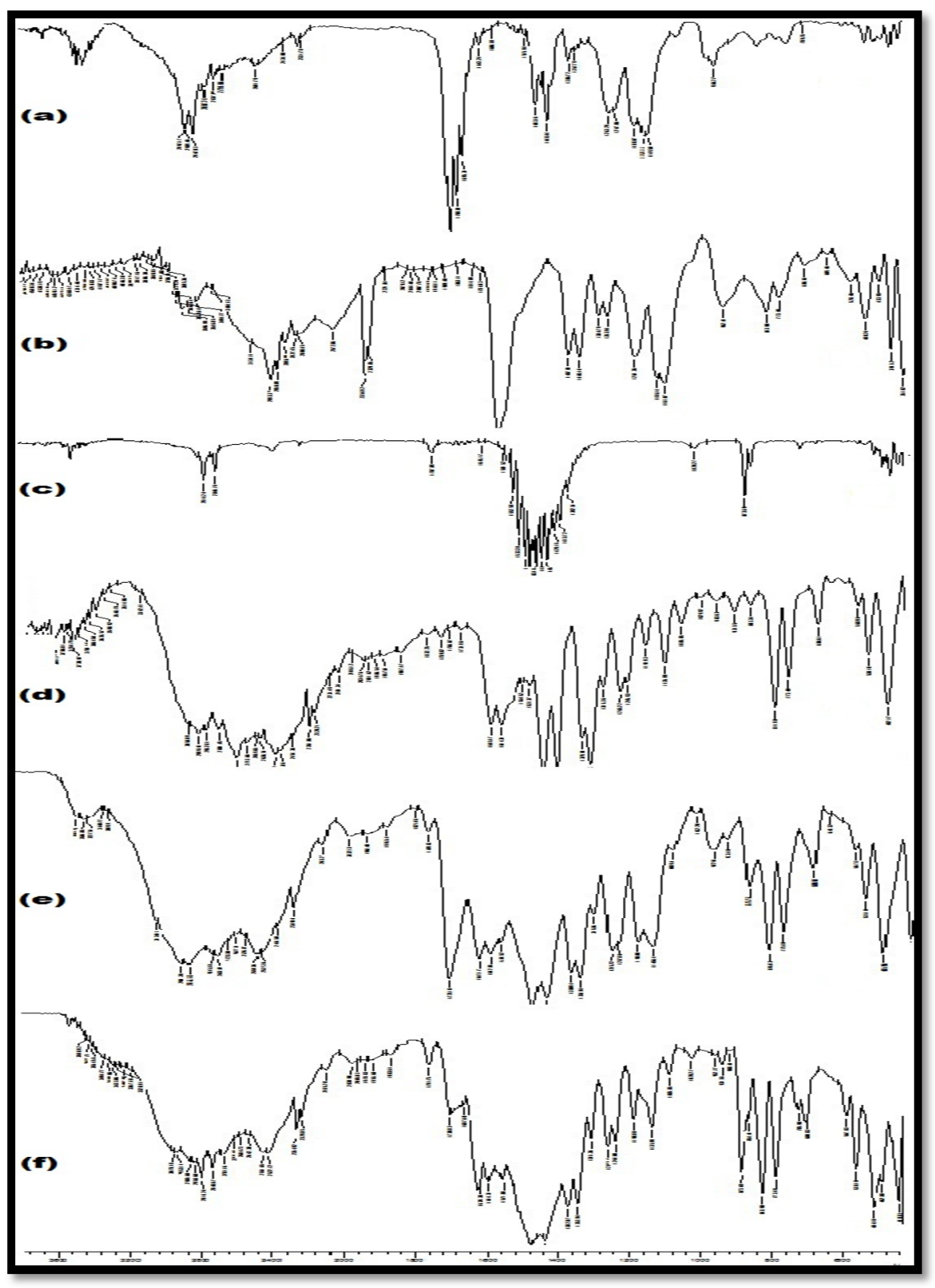

Fig. 1: FT-IR Graphs of a) eudragit S 100; b) eudragit L 100; c) Mg stearate; d) mesalazine; e) mesalazine+eudragit S 100; f) mesalazine+eudragit L 100

\section{DSC studies}

DSC thermogram of pure drug mesalazine (fig. 2a) showed a characteristic exothermic peak at $294.52{ }^{\circ} \mathrm{C}$, which was within the range of melting point of mesalazine. Eudragit L-100 and eudragit S-100 exhibited a similar exothermic peak at $239.84{ }^{\circ} \mathrm{C}$ and $222.86{ }^{\circ} \mathrm{C}$ respectively (fig. $2 \mathrm{~b}$ and $2 \mathrm{c}$ ). The observed melting point range was found to be in close proximity to the 
values reported. Mesalazine peak was found at $287.11^{\circ} \mathrm{C}$ in a physical mixture of mesalazine with eudragit S-100(fig. 2d) and in a physical mixture of mesalazine with eudragit L-100, a characteristic peak was observed at $289.11^{\circ} \mathrm{C}$ (fig. 2e). This study confirmed that there was no interaction between the drug and polymers used.

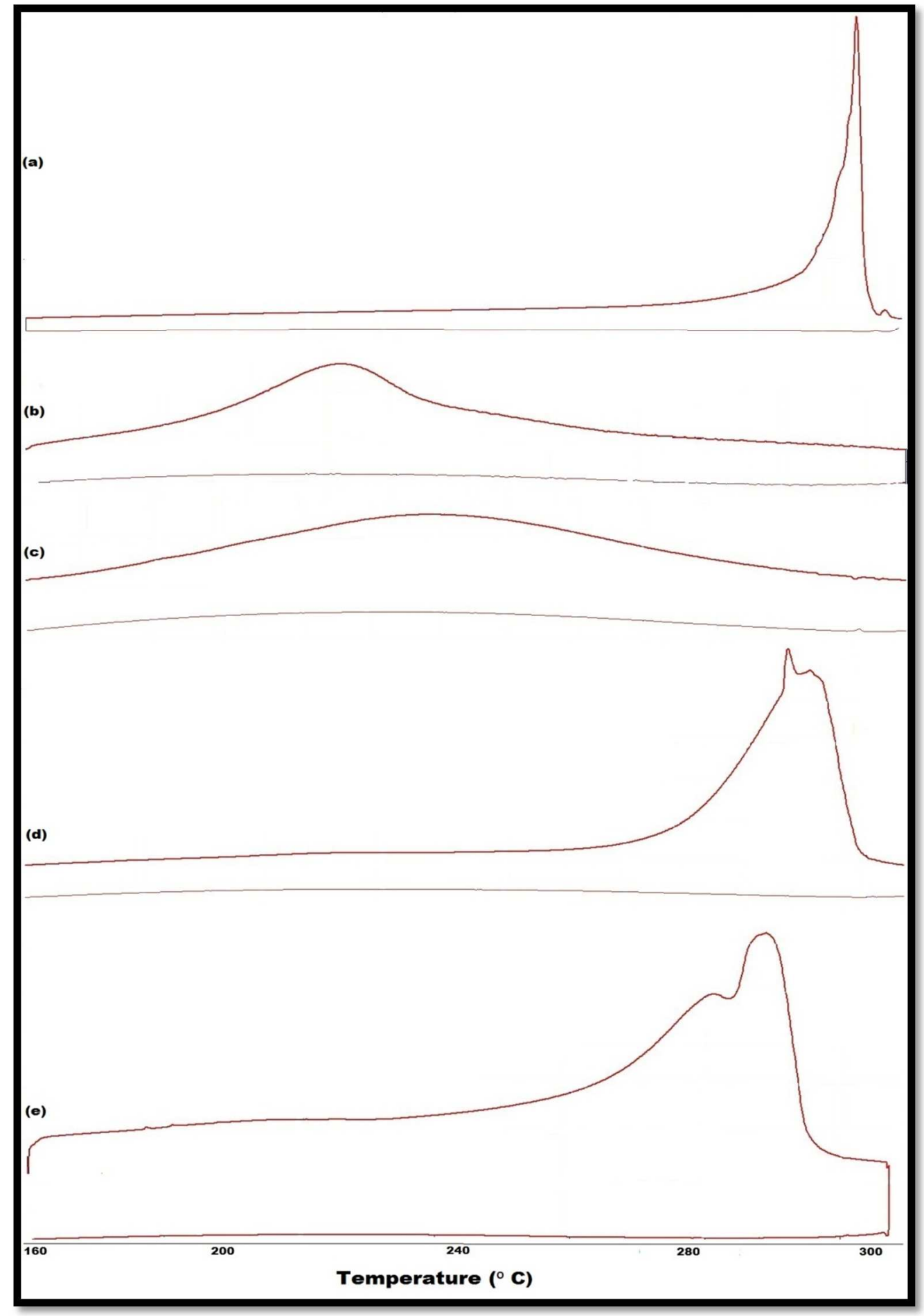

Fig. 2: DSC Curves of a) mesalazine; b) eudragit L 100; c) eudragit S 100; d) mesalazine+eudragit S 100; e) mesalazine+eudragit L 100

\section{XRD studies}

The powder XRD curves were represented in the fig. 3 . The $2 \theta$ values from the powder XRD studies for mesalazine was found to be $14.956^{\circ}$ (fig. 3a) and a sharp intense peak indicated the crystallinity of the drug. The $2 \theta$ value of eudragit L- 100 was found to be $42.709^{\circ}$ (fig. 3 b) indicating its crystalline nature. The $2 \theta$ value of eudragit S-100 was found to be $14.487^{\circ}$ (fig. 3c) and confirmed its amorphous nature by a broad peak. A physical mixture of mesalazine with Eudragit S-100 showed a sharp intense peak at $15.167^{\circ}$ (represented in the fig. $3 \mathrm{~d}$ ) and that of mesalazine with eudragit L-100 showed a sharp peak at $15.084^{\circ}$ (represented in the fig. 3 e) indicating that the drug and the polymer existed in the crystalline state. 


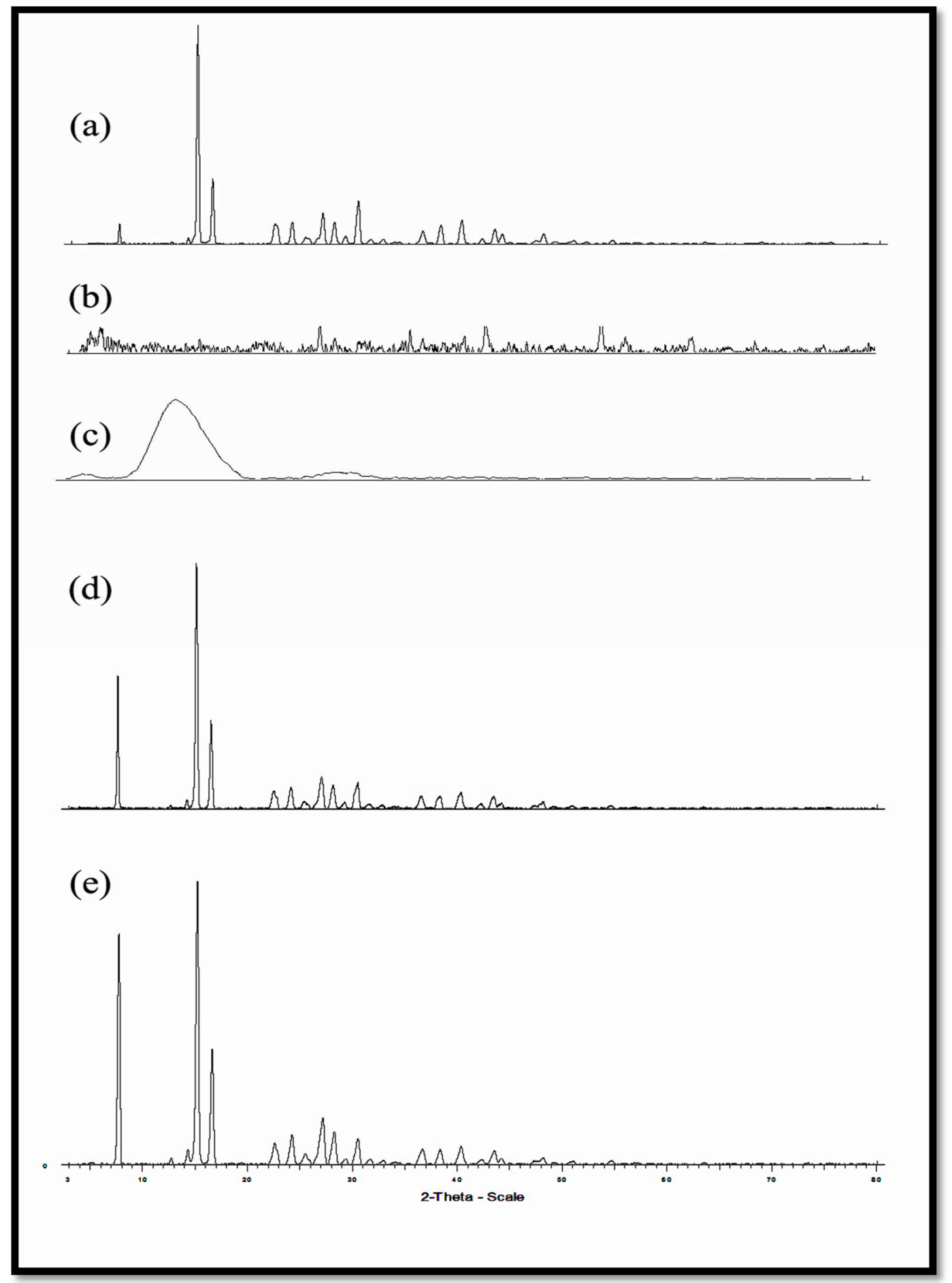

Fig. 3: XRD Curves of a) mesalazine; b) eudragit L 100; c) eudragit S 100; d) mesalazine+eudragit S 100; e) mesalazine+eudragit L 100 characterization of mesalazine microspheres

The percentage yield ranged from $87.96 \%$ to $99.78 \%$ for eudragit S 100 microspheres and $86.79 \%$ to $95.86 \%$ for eudragit L 100 microspheres. Particle size was found to be in the range of $265.26 \pm 1.9 \mu \mathrm{m}$ to $301.21 \pm 0.2 \mu \mathrm{m}$ with eudragit $\mathrm{S} 100$ microspheres and $295.09 \pm 2.8 \mu \mathrm{m}$ to $367.93 \pm 2.3 \mu \mathrm{m}$ with eudragit $\mathrm{L} 100$ microspheres. The percent drug entrapment was found to be in the range of $85.56 \%$ to $99.12 \%$ for all formulations of eudragit S 100 microspheres and $79.52 \%$ to $96.54 \%$ for formulations made with eudragit L 100. The granular analysis of the prepared microspheres was performed and flow property was found to be best for formulation F5 (22 $\left.22^{0} 4\right)$ using eudragit S 100 and for formulation F8 ( $24^{0}$ 93) using eudragit L 100 . Bulk density was found to be least for formulation F10 at $0.3526 \mathrm{~g} / \mathrm{cc}$ and maximum for formulation F6 at $0.4968 \mathrm{~g} / \mathrm{cc}$. Tap density was found to be in the range of $0.4850 \mathrm{~g} / \mathrm{cc}$ to $0.7443 \mathrm{~g} / \mathrm{cc}$ for all the prepared microsphere formulations. The bulkiness was observed to be in the range of 2.0128 to 2.8360 . The Carr's index was found to be in the range of $20 \%$ to $46.1 \%$ and Hausner's ratio was found to be in the range of 1.25 to 1.85 for all the microsphere formulations. The results were shown in table 2 . 
Table 2: Characterization of prepared microspheres

\begin{tabular}{|c|c|c|c|c|c|c|c|c|c|}
\hline $\begin{array}{l}\text { Formulation } \\
\text { code }\end{array}$ & $\begin{array}{l}\text { Percentage } \\
\text { yield* }\end{array}$ & $\begin{array}{l}\text { Particle } \\
\text { size }(\mu \mathrm{m})^{*}\end{array}$ & $\begin{array}{l}\text { Drug } \\
\text { entrapment } \\
(\%)^{*}\end{array}$ & $\begin{array}{l}\text { Bulk } \\
\text { density } \\
\text { (g/cc) }\end{array}$ & $\begin{array}{l}\text { Tap } \\
\text { density } \\
(\mathrm{g} / \mathrm{cc})^{*}\end{array}$ & $\begin{array}{l}\text { Hausner's } \\
\text { ratio* }\end{array}$ & $\begin{array}{l}\text { Angle of } \\
\text { repose } \\
(\theta)\end{array}$ & $\begin{array}{l}\text { Carr's } \\
\text { index } \\
(\%)^{*}\end{array}$ & $\begin{array}{l}\text { Bulkiness } \\
\text { (ml/g)* }\end{array}$ \\
\hline F1 & $95.7 \pm 0.90$ & $275.35 \pm 1.6$ & $85.56 \pm 0.36$ & $0.385 \pm 0.04$ & $0.616 \pm 0.04$ & $1.61 \pm 0.5$ & $25^{0} 05$ & $37.5 \pm 0.3$ & $2.59 \pm 0.61$ \\
\hline $\mathrm{F} 2$ & $87.9 \pm 0.65$ & $290.86 \pm 3.2$ & $90.11 \pm 0.45$ & $0.363 \pm 0.03$ & $0.485 \pm 0.06$ & $1.33 \pm 0.6$ & $26^{0} 15$ & $25.1 \pm 0.4$ & $2.74 \pm 0.54$ \\
\hline F3 & $89.9 \pm 0.74$ & $301.21 \pm 0.2$ & $92.56 \pm 0.98$ & $0.428 \pm 0.02$ & $0.588 \pm 0.03$ & $1.37 \pm 0.4$ & $28^{0} 49$ & $27.28 \pm 0.2$ & $2.33 \pm 0.32$ \\
\hline $\mathrm{F} 4$ & $91.5 \pm 0.63$ & $270.85 \pm 2.5$ & $95.39 \pm 0.35$ & $0.460 \pm 0.04$ & $0.575 \pm 0.04$ & $1.25 \pm 0.3$ & $25^{0} 96$ & $20.3 \pm 0.3$ & $2.17 \pm 0.45$ \\
\hline F5 & $99.7 \pm 0.84$ & $265.26 \pm 1.9$ & $99.12 \pm 0.47$ & $0.456 \pm 0.03$ & $0.580 \pm 0.05$ & $1.27 \pm 0.5$ & $22^{0} 43$ & $21.4 \pm 0.4$ & $2.19 \pm 0.24$ \\
\hline F6 & $86.7 \pm 0.37$ & $295.09 \pm 2.8$ & $79.52 \pm 0.55$ & $0.496 \pm 0.05$ & $0.744 \pm 0.03$ & $1.49 \pm 0.6$ & $26^{0} 45$ & $33.25 \pm 0.6$ & $2.01 \pm 0.30$ \\
\hline F7 & $88.9 \pm 0.91$ & $367.93 \pm 2.3$ & $84.65 \pm 0.87$ & $0.389 \pm 0.03$ & $0.678 \pm 0.04$ & $1.74 \pm 0.5$ & $27^{0} 58$ & $42.58 \pm 0.3$ & $2.56 \pm 0.80$ \\
\hline F8 & $95.8 \pm 0.57$ & $280.47 \pm 0.5$ & $96.54 \pm 0.49$ & $0.406 \pm 0.02$ & $0.676 \pm 0.04$ & $1.66 \pm 0.4$ & $24^{0} 93$ & $39.99 \pm 0.2$ & $2.46 \pm 0.30$ \\
\hline F9 & $93.7 \pm 0.69$ & $336.21 \pm 2.8$ & $95.65 \pm 0.34$ & $0.401 \pm 0.05$ & $0.685 \pm 0.03$ & $1.70 \pm 0.4$ & $30^{0} 57$ & $41.38 \pm 0.4$ & $2.49 \pm 0.20$ \\
\hline F10 & $89.9 \pm 0.78$ & $295.17 \pm 1.4$ & $91.58 \pm 0.26$ & $0.352 \pm 0.03$ & $0.654 \pm 0.02$ & $1.85 \pm 0.2$ & $25^{0} 46$ & $46.10 \pm 0.2$ & $2.83 \pm 0.60$ \\
\hline
\end{tabular}

$*(n=3)$ (average $\pm S D)$

\section{SEM studies}

Scanning electron microscopy of the formulations revealed that the surface morphology of the prepared microspheres was found to be spherical. The surface of the spheres was rough with abrasions on it (fig. $4 \mathrm{a}$ and $4 \mathrm{~b}$ ).

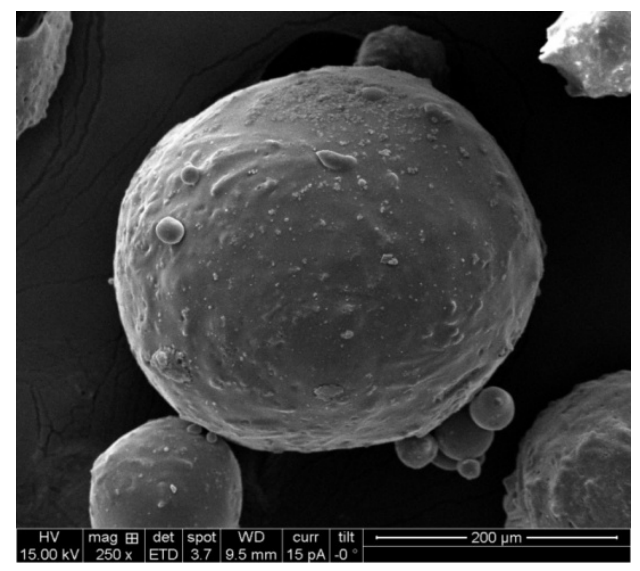

Fig. 4a: Microspheres of eudragit S-100

\section{In vitro drug release studies}

The percentage drug release was found best in formulation F5 with $101.45 \%$ release and least drug release was observed in formulation F2 with $94.39 \%$ at the end of $11^{\text {th }} \mathrm{h}$ for microspheres prepared with eudragit S 100. The drug release was found best in formulation F8 with $99.69 \%$ and least drug release was observed with $96.66 \%$ in formulation F10 to the end of $11 \mathrm{~h}$ for microspheres prepared with eudragit L 100. The plot for cumulative drug release profiles for all the mesalazine formulations prepared using eudragit S 100 and L 100 was shown in the fig. 5 and 6 . The drug release for the formulations was found to be less than $30 \%$ till the end of $4^{\text {th }}$ hour after which there is a rapid release of drug by the end of $11 \mathrm{~h}$. Even if the microspheres did not burst, large swelling occurred and thus increased matrix porosity. These findings comply well with the higher drug to polymer ratio used in formulations [17]. This release shows the $\mathrm{pH}$ sensitivity of the polymer which releases the drug only in the colon region.

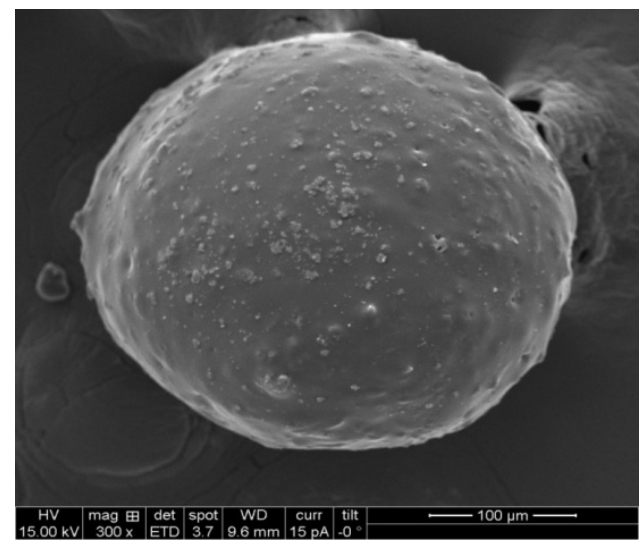

Fig. 4b: Microspheres of eudragit L-100

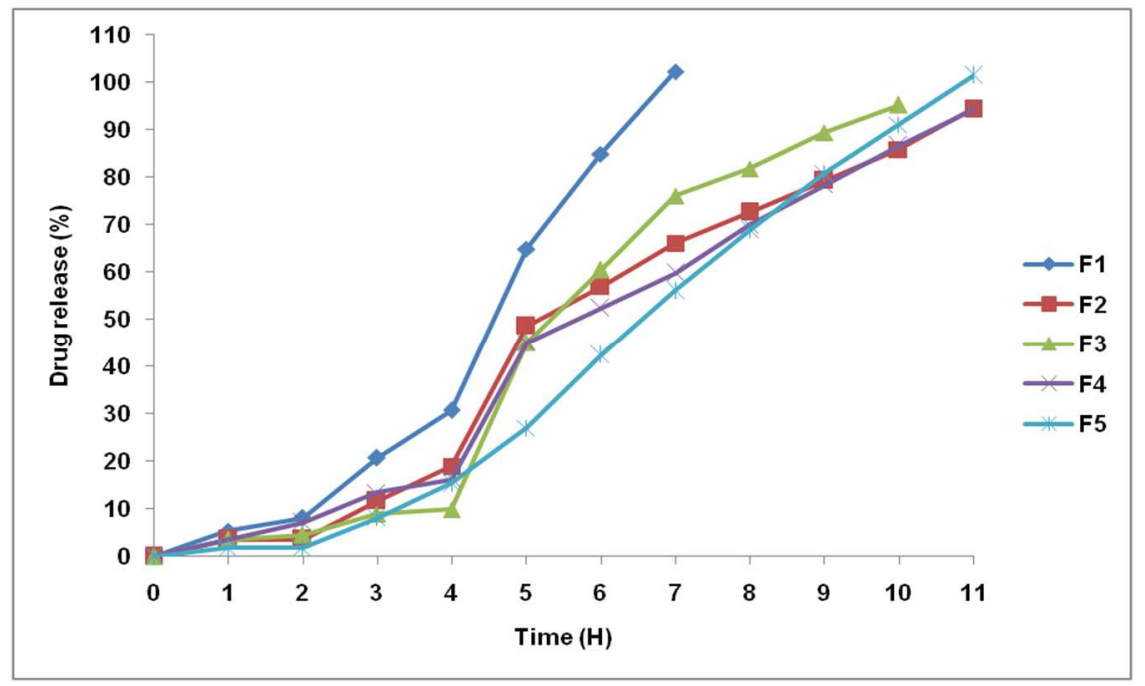

Fig. 5: Drug release profile of formulations with eudrait $S-100(n=3)$ 


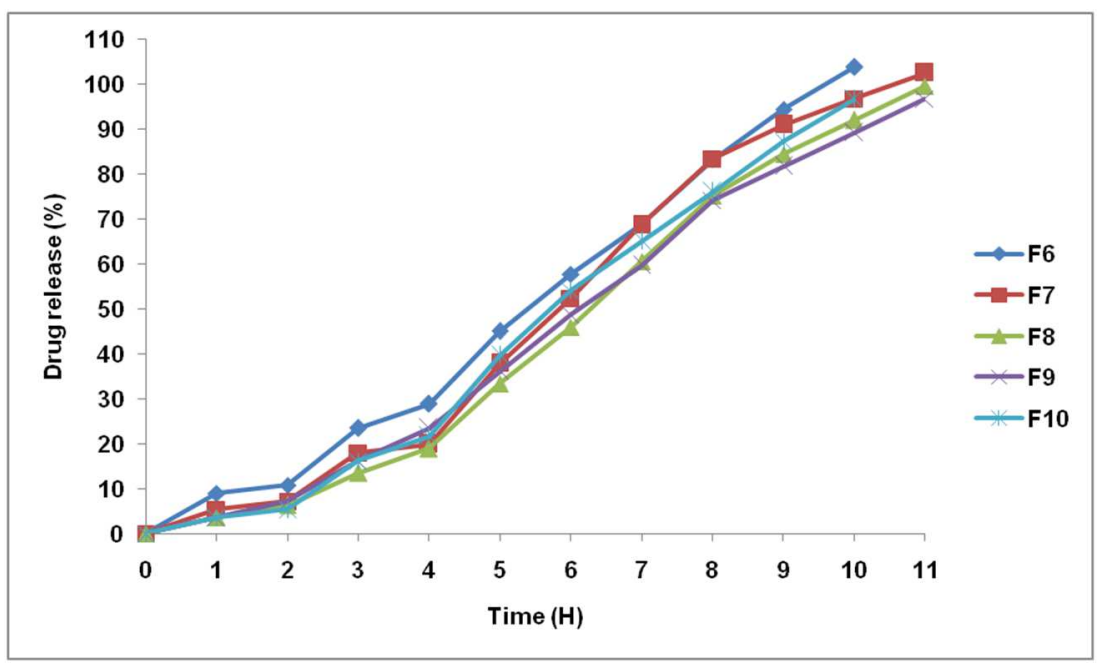

Fig. 6: Drug-release profile of formulations with eudragit $L-100(n=3)$

\section{Drug release kinetics}

The best fit model was found to be Peppas for formulations F1, F2, F5, F7, F8 F9 and F10, whereas formulations F3, F4, F6 showed zero order release kinetics.

\section{Effect of process variables on formulations}

Among the mesalazine microspheres prepared using Eudragit S 100, formulation $\mathrm{F} 5$ was selected as the best and from the formulations prepared using Eudragit L 100, formulation F8 was selected as the best based on their in vitro drug release profile. The effects of process variables on these 2 formulations F5 and F8 were studied.
The formulation variables tested were a. The concentration of Span 80 and b. RPM (table 3 and 4).

Effect of concentration of span 80 on mesalazine loaded eudragit $\mathbf{S} 100$ microspheres

Three formulations F11, F12 and F13 were prepared using mesalazine and eudragit S 100 in the ratio of 1:5 and varying span 80 concentration by $1 \%, 1.5 \%$ and $2.5 \%$ but fixed RPM at 1500 . As the concentration of span 80 increased, the particle size of the microsphere formulations increased, whereas the percent drug entrapment decreased. This could be due to the increase in the viscosity of the medium.

Table 3: Effect of variable parameters on formulation with eudragit S-100

\begin{tabular}{lllll}
\hline S. No. & Formulation code & Drug: polymer ratio & Stirring speed & Emulsifier concentration (\%) \\
\hline 1 & F11 & $1: 5$ & 1500 & 1 \\
2 & F12 & $1: 5$ & 1500 & 1.5 \\
3 & F13 & $1: 5$ & 1500 & 2.5 \\
4 & F14 & $1: 5$ & 1000 & 2 \\
5 & F15 & $1: 5$ & 2000 & 2 \\
6 & F16 & $1: 5$ & 2500 & 2 \\
\hline
\end{tabular}

Table 4: Effect of variable parameters on formulation with eudragit L-100

\begin{tabular}{lllll}
\hline S. No. & Formulation code & Drug: polymer ratio & Stirring speed & Emulsifier concentration (\%) \\
\hline 1 & F17 & $1: 3$ & 1000 & 2 \\
2 & F18 & $1: 3$ & 2000 & 2 \\
3 & F19 & $1: 3$ & 2500 & 2 \\
4 & F20 & $1: 3$ & 1500 & 1 \\
5 & F21 & $1: 3$ & 1500 & 1.5 \\
6 & F22 & $1: 3$ & 1500 & 2.5 \\
\hline
\end{tabular}

\section{Effect of RPM on mesalazine loaded eudragit S 100 microspheres}

Three formulations F14, F15 and F16 were prepared using mesalazine and eudragit $S 100$ in the ratio of $1: 5$ with fixed span concentration of $2 \%$ but, by varying RPM viz. 1000, 2000 and 2500 . As the RPM increased, the particle size of the microsphere formulations decreased and the percent drug entrapment increased. This could be due to the increase in the viscosity of the medium.

\section{Effect of RPM on mesalazine loaded eudragit L 100 microspheres}

Three formulations F17, F18 and F19 were prepared with mesalazine and eudragit L 100 in the ratio of 1:3 with fixed span concentration of $2 \%$ but, by varying RPM viz. 1000, 2000 and 2500 respectively. As the RPM increased, the particle size of the microsphere formulations decreased, whereas the percent drug entrapment increased. This could be due to the increase in the viscosity of the medium.

Effect of concentration of Span 80 on mesalazine loaded eudragit L 100 microspheres

Three formulations F20, F21 and F22 were prepared using mesalazine and eudragit L 100 in the ratio of $1: 3$ and with a fixed RPM of 1500 but, by varying span concentration viz. $1 \%, 1.5 \%$ and $2.5 \%$ respectively. As the concentration of span 80 increased, the particle size of the microsphere formulations decreased, but after a certain extent, the particle size increased. A similar effect was found in case of percent drug entrapment which decreased initially and later increased. This is due to better stabilisation of internal droplets 
with an increase of surfactant concentration preventing coalescence. Also when more amount of surfactant was added, there is an accelerated dispersion of microcapsules in the microencapsulation system.

\section{Characterization of mesalazine microspheres for optimized formulations}

The optimised microsphere formulations were characterized for parameters such as percentage yield, particle size, percent drug entrapment, granular analysis and the results were shown in table 5. The percentage yield of microspheres ranged from $87.36 \%$ to $98.78 \%$ for formulations prepared with eudragit S 100 and $85.42 \%$ to $98.59 \%$ for formulations prepared with eudragit L 100 . The particle size was found to be ranging from $227.12 \pm 1.4 \mu \mathrm{m}$ to
$378.89 \pm 2.5 \mu \mathrm{m}$ for eudragit $\mathrm{S} 100$ microspheres and $230.54 \pm 3.4 \mu \mathrm{m}$ to the $345.57 \pm 2.4 \mu \mathrm{m}$ range for eudragit $\mathrm{L} 100$ microspheres. The percent drug entrapment was found to be in the range of $89.78 \%$ to $98.54 \%$ for eudragit S 100 microspheres and $84.32 \%$ to $98.97 \%$ for eudragit L 100 microspheres. The flow property was found to be best for formulation F16 $\left(23^{\circ} 45^{\prime}\right)$ using eudragit S 100 and for formulation F20 $\left(23^{0} 29^{\prime}\right)$ using eudragit L 100 . Bulk density was found to be least for formulation F12 at $0.2800 \mathrm{~g} / \mathrm{cc}$ and maximum for formulation F16 at $0.4200 \mathrm{~g} / \mathrm{cc}$. Tap density was found to be in the range of $0.3925 \mathrm{~g} / \mathrm{cc}$ to $0.6300 \mathrm{~g} / \mathrm{cc}$ for all the prepared microsphere formulations. The bulkiness was observed to be in the range of 1.8308 to 3.5714 . The Carr's index was found to be in the range of $22.57 \%$ to $42.86 \%$ and Hausner's ratio was found to be in the range of 1.2478 to 1.7503 for all the prepared microsphere formulations.

Table 5: Characterization of optimised mesalazine microsphere formulations

\begin{tabular}{|c|c|c|c|c|c|c|c|c|c|}
\hline $\begin{array}{l}\text { Formulation } \\
\text { code }\end{array}$ & \% yield* & $\begin{array}{l}\text { Particle } \\
\text { size* } \\
(\mu \mathrm{m})\end{array}$ & $\begin{array}{l}\text { Drug } \\
\text { entrapment } \\
(\%)^{*}\end{array}$ & $\begin{array}{l}\text { Bulk } \\
\text { density } \\
\text { (g/cc) }\end{array}$ & $\begin{array}{l}\text { Tap } \\
\text { density } \\
\text { (g/cc) }\end{array}$ & $\begin{array}{l}\text { Bulkiness } \\
\text { (ml/g)* }\end{array}$ & $\begin{array}{l}\text { Carr's } \\
\text { index } \\
(\%)^{*}\end{array}$ & $\begin{array}{l}\text { Hausner's } \\
\text { ratio* }\end{array}$ & $\begin{array}{l}\text { Angle of } \\
\text { repose } \\
(\theta)\end{array}$ \\
\hline F11 & $98.78 \pm 0.65$ & $259.42 \pm 1.4$ & $98.54 \pm 0.35$ & $0.384 \pm 0.04$ & $0.598 \pm 0.03$ & $2.60 \pm 0.42$ & $35.76 \pm 0.3$ & $1.55 \pm 0.4$ & $29^{0} 78^{\prime}$ \\
\hline F12 & $91.35 \pm 0.34$ & $287.78 \pm 3.2$ & $92.54 \pm 0.24$ & $0.280 \pm 0.04$ & $0.392 \pm 0.06$ & $3.57 \pm 0.31$ & $22.57 \pm 0.4$ & $1.40 \pm 0.3$ & $24^{0} 25^{\prime}$ \\
\hline F13 & $95.56 \pm 0.21$ & $346.67 \pm 1.8$ & $94.86 \pm 0.39$ & $0.314 \pm 0.06$ & $0.448 \pm 0.04$ & $3.18 \pm 0.28$ & $29.98 \pm 0.3$ & $1.42 \pm 0.2$ & $25^{0} 26^{\prime}$ \\
\hline F14 & $87.36 \pm 0.47$ & $378.89 \pm 2.5$ & $89.78 \pm 0.21$ & $0.318 \pm 0.03$ & $0.557 \pm 0.05$ & $3.13 \pm 0.36$ & $42.86 \pm 0.2$ & $1.75 \pm 0.4$ & $30^{\circ} 18^{\prime}$ \\
\hline F15 & $90.34 \pm 0.39$ & $281.36 \pm 0.9$ & $91.35 \pm 0.19$ & $0.285 \pm 0.04$ & $0.392 \pm 0.02$ & $3.50 \pm 0.34$ & $27.28 \pm 0.6$ & $1.37 \pm 0.5$ & $24^{0} 08^{\prime}$ \\
\hline F16 & $94.98 \pm 0.22$ & $227.12 \pm 1.4$ & $97.89 \pm 0.41$ & $0.420 \pm 0.03$ & $0.630 \pm 0.04$ & $2.38 \pm 0.43$ & $33.33 \pm 0.7$ & $1.54 \pm 0.6$ & $23^{0} 45^{\prime}$ \\
\hline F17 & $85.42 \pm 0.41$ & $345.57 \pm 2.4$ & $84.32 \pm 0.53$ & $0.359 \pm 0.05$ & $0.567 \pm 0.04$ & $2.78 \pm 0.17$ & $36.74 \pm 0.5$ & $1.58 \pm 0.4$ & $26^{0} 78^{\prime}$ \\
\hline F18 & $92.56 \pm 0.30$ & $276.64 \pm 2.8$ & $94.58 \pm 0.44$ & $0.381 \pm 0.06$ & $0.579 \pm 0.05$ & $2.62 \pm 0.26$ & $34.12 \pm 0.6$ & $1.51 \pm 0.5$ & $26^{0} 91^{\prime}$ \\
\hline F19 & $89.56 \pm 0.39$ & $230.54 \pm 3.4$ & $91.56 \pm 0.37$ & $0.360 \pm 0.04$ & $0.478 \pm 0.06$ & $2.77 \pm 0.19$ & $24.62 \pm 0.5$ & $1.32 \pm 0.3$ & $28^{0} 54^{\prime}$ \\
\hline F20 & $96.52 \pm 0.56$ & $298.65 \pm 1.6$ & $97.93 \pm 0.24$ & $0.546 \pm 0.03$ & $0.681 \pm 0.04$ & $1.83 \pm 0.21$ & $24.78 \pm 0.4$ & $1.24 \pm 0.3$ & $23^{0} 29^{\prime}$ \\
\hline F21 & $93.56 \pm 0.73$ & $256.48 \pm 2.2$ & $94.35 \pm 0.69$ & $0.293 \pm 0.02$ & $0.470 \pm 0.06$ & $3.40 \pm 0.31$ & $37.51 \pm 0.6$ & $1.60 \pm 0.2$ & $27^{0} 49^{\prime}$ \\
\hline F22 & $98.59 \pm 0.64$ & $310.48 \pm 2.4$ & $98.97 \pm 0.36$ & $0.389 \pm 0.03$ & $0.545 \pm 0.05$ & $2.56 \pm 0.37$ & $28.63 \pm 0.3$ & $1.40 \pm 0.4$ & $24^{0} 36^{\prime}$ \\
\hline
\end{tabular}

* $(\mathrm{n}=3) ;$ (average $\pm \mathrm{SD})$

\section{In vitro drug release studies}

The percentage drug release was found to be best in microsphere formulation F13 with $100.51 \%$ release and least drug release was observed in formulation F16 with $89.72 \%$ at the end of $12^{\text {th }}$ hour using eudragit $S 100$ as a polymer. The drug release was found best in formulation F20 with $93.42 \%$ and least drug release was observed with $73.25 \%$ in formulation F22 to the end of $12 \mathrm{~h}$ using eudragit L 100 as a polymer. The plot for cumulative drug release profiles for all the formulations prepared using eudragit S 100 and $\mathrm{L} 100$ were shown in the fig. 7, 8. The drug release for the formulations was found to be less than $25 \%$ till the end of $4^{\text {th }}$ hour after which there is a rapid release of drug by the end of $12 \mathrm{~h}$. This release shows the $\mathrm{pH}$ sensitivity of the polymer which releases the drug only in the colon region.

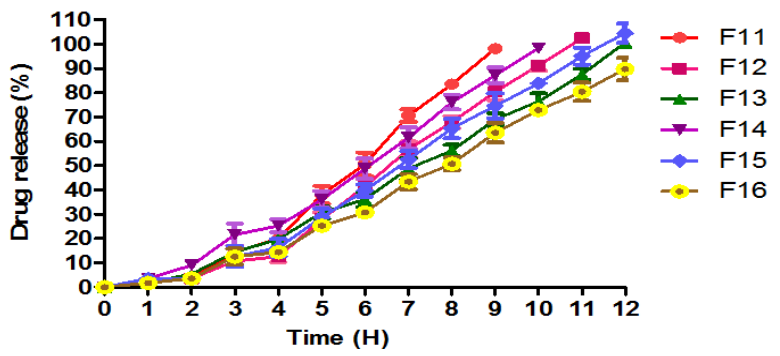

Fig. 7: Drug-release profile of formulation with varying surfactant concentration and RPM with polymer eudragit $S 100(n=3)$

\section{Drug release kinetics}

The best fit model was found to be Peppas for formulations F11, F12, F13, F14, F15, F16, F17, F18, F19, F20 and F22, whereas formulations F21 showed zero order release kinetics.

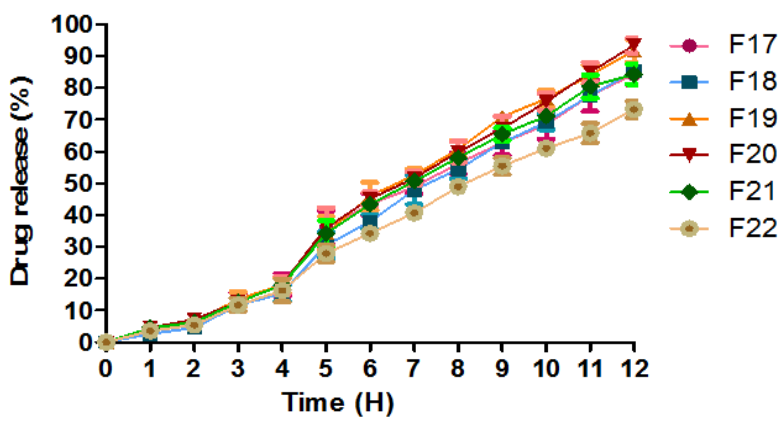

Fig. 8: Drug-release profile of formulation with varying surfactant concentration and RPM with polymer eudragit $L$ $100(n=3)$

\section{Stability studies}

Table 6 represents the results of stability studies for the prepared microsphere formulations. The drug entrapment efficiency and the physical appearance of the microspheres were examined for formulations F13 for eudragit S 100 and F20 for eudragit L100 at various time intervals of 2,4 and 6 mo by storing them in accelerated conditions $\left(40{ }^{\circ} \mathrm{C} \pm 2{ }^{\circ} \mathrm{C} / 75 \% \mathrm{RH} \pm 5 \%\right)$. The results of percentage drug entrapment efficiency and physical appearance of both the formulations were close to that of initial data with very slight variations suggesting that it has an acceptable stability on storage. The similarity factor ( $f 2$ ) for a modified release dosage form was used as a basis to compare the dissolution profiles of the best formulations at 2, 4 and 6 mo with the initial day. The similarity factor values for 2, 4 and 6 mo were found to be $67.89,64.25$ and 60.32 respectively indicating the closest fit to the initial day dissolution profile. 
Table 6: Data for stability study indicating percentage drug content

\begin{tabular}{llll}
\hline Formulation code & \multicolumn{2}{l}{ Percentage drug content } & \\
\cline { 2 - 4 } & 0 Time & $\mathbf{2}^{\text {nd }} \mathbf{m o}$ & $\mathbf{4}^{\text {th }} \mathbf{m o}$ \\
\hline F13 & $100.51 \pm 0.75$ & $100.20 \pm 0.54$ & $99.94 \pm 0.35$ \\
F20 & $93.42 \pm 0.95$ & $93.25 \pm 1.20$ & $93.02 \pm 0.68$ \\
similarity factor (f2) & - & 67.89 & 64.25 \\
\hline
\end{tabular}

$(n=6)$ (average $\pm S D)$

\section{CONCLUSION}

Sustained release mesalazine microspheres for colon targeting were prepared by a non-aqueous solvent evaporation method using $\mathrm{pH}$ sensitive polymers such as eudragit S 100 and eudragit L 100. The microspheres prepared with polymers eudragit S100 and eudragit L 100 were found suitable for colonic release of mesalazine resisting drug release in gastric medium, minimising release in the upper intestinal region and showing maximum release in the colonic region. The effect of variable parameters like concentration of span 80 and RPM was tested on the best formulation and further characterised. Thus the developed formulations prove to be promising for the colon targeted drug delivery of mesalazine and thereby facilitating in the management of ulcerative colitis and inflammatory bowel disease.

\section{ACKNOWLEDGEMENT}

The authors are thankful to The Dean, Faculty of Pharmacy, MSRUAS for providing necessary facilities to carry out the research work. The authors thank Indian Institute of Science (IISc), Bangalore for carrying out DSC, XRD and SEM studies.

\section{CONFLICT OF INTERESTS}

\section{Declared none}

\section{REFERENCES}

1. Kumar KPS, Bhowmik D, Srivastava S, Paswan S, Dutta AS. Sustained release drug delivery system potential. Pharm Innovat 2012;1:48-60.

2. Dehghan S, Aboofazeli R, Avadi M, Khaksar R. Formulation optimization of nifedipine-containing microspheres using factorial design. Afr J Pharm Pharmacol 2010;4:346-54.

3. Patel JK, Patel RP, Amin AF, Patel MM. Formulation and evaluation of mucoadhesive glipizide microspheres. AAPS PharmSciTech 2005;6:E49-E55.

4. Huyghebaert N, Vermeire A, Remon JP. In vitro evaluation of coating polymers for enteric coating and human ileal targeting. Int J Pharm 2005;298:26-37.

5. Gupta VK, Beckert E, Price JC. A novel pH-and time based multiunit potential colonic drug delivery system. Int J Pharm 2001;213:93-102.

6. Deveswaran R, Manavalan R, Madhavan V, Bharath S. Development and evaluation of aceclofenac loaded ethyl cellulose microspheres. Asian J Pharm Sci 2012;7:50-7.
7. Hanauer SB. Aminosalicylates in inflammatory bowel disease. Aliment Pharmacol Ther 2004;20:60-5.

8. Podolsky DK. Inflammatory bowel disease. N Engl J Med 2002;347:417-29.

9. Mahida YR, Lamming CE, Gallagher A, Hawthorne AB, Hawkey CJ. 5-aminosalicylic acid is a potent inhibitor of interleukin 1 beta production in organ culture of colonic biopsy specimens from patients with inflammatory bowel disease. Gut 1991;32:50-4.

10. Cominelli F, Nast CC, Duchini A, Lee M. Recombinant interleukin-1 receptor antagonist blocks the proinflammatory activity of endogenous interleukin-1 in rabbit immune colitis. Gastroenterology 1992;103:65-71.

11. Swapna A, Mohd AB, Wamorkar V, Swathimutyam P. Formulation and evaluation of mesalamine microspheres for colon targeted drug delivery system. J Pharm Res 2011;4:1670-2.

12. Najmuddin M, Sachin S, Asgar Ali, Patel V, Khan T. Formulation and in vitro evaluation of floating microspheres of ketoprofen prepared by emulsion solvent diffusion method. Int J Appl Pharm 2010;2:13-7.

13. Aulton ME. Pharmaceutics: The science of dosage form design. $9^{\text {th }}$ Edition. London: Churchill Livingstone; 1999. p. 610.

14. Tong Dang, Ying Cui, Yan-Dong Chen, Xian-Mei Meng, Bo-Fu Tang, Jin-BaoWu. Preparation and characterization of colonspecific microspheres of diclofenac for colorectal cancer. Trop J Pharm Res 2015;14:1541-7.

15. Grimm W. Extension of the international conference on harmonization tripartite guideline for stability testing of new drug substances and products to countries of climatic zones III and IV. Drug Dev Ind Pharm 1998;24:313-25.

16. Sandeep K, Arun N. Formulation, optimization and in vitro evaluation of gastroretentive mucoadhesive microspheres of furosemide. Int J Pharm Pharm Sci 2016;8:392-8.

17. Khaled Al-Tahami. Preparation, characterization, and in vitro release of ketoprofen loaded alginate microspheres. Int J Appl Pharm 2014;6:9-12.

\section{How to cite this article}

- Katta Rajesh, R Deveswaran, S Bharath, BV Basavaraj. Development of mesalazine microspheres for colon targeting. Int J Appl Pharm 2017;9(4):1-9. 